\title{
One doctor's misfortune boosts TB treatment activism
}

It's Christmas; you're in a hospital isolation ward, sleep-deprived and depressed, bilious and sometimes swallowing your own vomit to keep the pills down, with a painful $3 \mathrm{~cm}$ hole in your lung and slowly going deaf - that's how it was for one unfortunate Somerset West doctor two years ago.

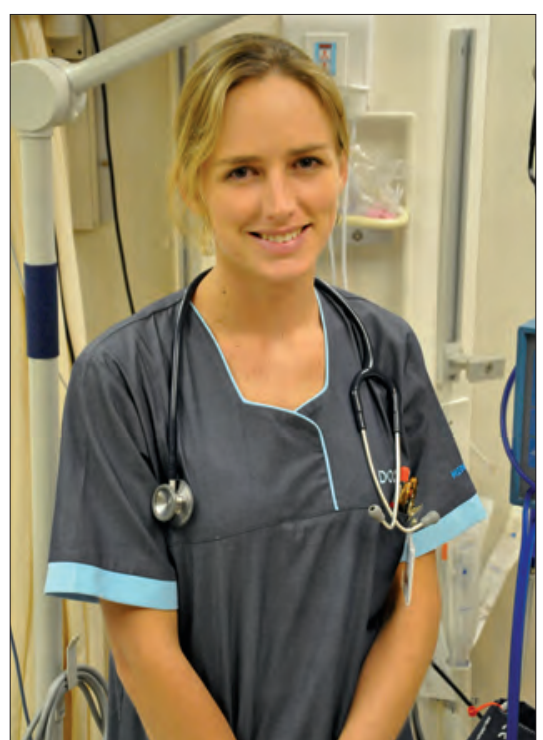

Dr Dalene von Delft.

Now remove aspiring paediatrician Dr Dalene von Delft's medical aid, her cutting edge collegial advice, a steadfast and supportive doctor-husband and an ability to persuade a major drug company to allow compassionate use of an as-yet unproven drug for multi-drug resistant $\mathrm{TB}$ - and you have the distilled experience of most MDR TB and XDR TB-infected South Africans. Von Delft counts her blessings because she knows that her struggle pales in comparison with most of her compatriots. Today she is alive and well, joining the privileged and/or lucky minority (estimates are $42 \%$ ) of South Africans cured of MDR TB. The worst three months of her treatment left her a changed person, and an activist clinician with strong ideas on the value of basic TB prevention methods that educationalists, peers and health system designers could implement so easily, thus saving hundreds of lives as the local epidemic burgeons.

Von Delft was one of four MDR patients whom researchers doing TB prevention trials were able to propose for special compassionate use of the new Phase II trial drug, bedaquiline, taking advantage of a several-month-long window that the Medicines Control Council (MCC) opened in 2011 to allow very limited importation of the drug. The alternatives for von Delft were permanent deafness, prematurely ending her career, or possibly even death. The MCC later controversially revoked the compassionate use of bedaquiline, fearing legal consequences and the lack of properly constituted scientific monitoring and treatment evaluation (the responsibility is left entirely on the shoulders of the applying medical professional). Nevertheless, the MCC allowed the foursome to (successfully) complete their treatment.

\section{Right place, time and person}

Von Delft's principal 'saviour' proved to be a colleague at Tygerberg Hospital, Professor Andreas Diacon, principal investigator of South Africa's largest bedaquiline trial and a consultant pulmonologist and medical biochemist. He motivated to the manufacturers (then Tibotec, now Janssen Research and Development) for use of their drug, given von Delft's unique circumstances. Both von Delft and her husband, Arne, doubt they would have 'got anywhere' without him, especially since Dalene was not eligible for the initial compassionate use criteria for the experimental drug. However, her prospective career loss and fast-degenerating hearing (a side effect of one of her seven drugs, the injectable amikacin) swung things in her favour. As Diacon later told Izindaba, 'I know them all [the drug manufacturers] and if I say she's a good patient [prospect] they have good reason to believe me. Diacon was unaware of the subsequent MCC controversy, after the global not-for-profit volunteer doctor agency Médecins Sans Frontières (MSF), as well as local TB and HIV treatment pioneers, made urgent appeals to re-open or fast-track wider compassionate-use approval.

Von Delft was working in the paediatric department of a large state hospital (where she believes she contracted the disease) when she began to experience what presented as a persistent post-nasal drip cough. After 3 weeks she began antibiotics, continuing to work night duty in the neonatal ward until a colleague insisted she have an X-ray. This revealed a large cavity in her upper lobe. The local head of occupational health

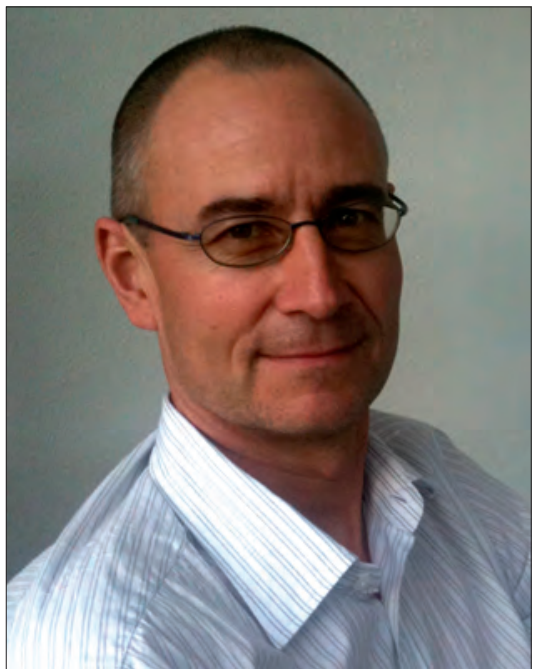

Professor Andreas Diacon.

advised her to submit a sputum sample, begin a TB drug course and return to work in 2 weeks - despite the fact that she worked in a respiratory ward. She told him that was simply unacceptable because she was worried about potential drug resistance, and insisted on further special investigations to ensure the correct diagnosis was made as soon as possible.

\section{Public sector a TB minefield}

Von Delft's post-cure vulnerability has forced her out of the public sector. Today she works in the emergency department of a nearby private hospital where the risks of coming into contact with $\mathrm{TB}$ are somewhat lower, though she religiously takes precautions when doing procedures such as intubations. The more costly and effective N95 respirator mask was a rare sight in her old job, though after her diagnosis it became policy for all medical staff to isolate any confirmed drugresistant TB patient and wear it when dealing with them. (The N95 protocol did not extend to undiagnosed MDR and XDR TB patients or those with drug-sensitive TB). Von Delft says she knows of at least 15 of her varsity medical colleagues who have contracted TB, though she is the first in her close circle of friends to contract MDR TB. Since she 'went public' with her experience (at the urging of the Treatment Action Group (TAG) and MSF), travelling to present at lung health conferences across the world, it seems that every day I hear of another healthcare worker getting TB or recurring TB'. 
On 28 December last year, the US Food and Drug Administration (FDA) approved bedaquiline for use in MDR TB in the USA - the catalyst for MSF to publicly urge the local MCC to reconsider the drug. The widely hailed US decision followed public hearings set up by the FDA, at which 18 leading independent public health experts aggressively interrogated presentations by the drug manufacturers and FDA staff before voting. The outcome was 18 - 0 for efficacy and $11-7$ for safety, the latter proving insufficient leeway for the local MCC. 'Just two votes either way, and you'd have had nine-nine for safety;, elaborates Diacon, who understands the local MCC's caution, given South Africa's burden of MDR and XDR TB.

\section{MCC errs on side of caution}

Says Professor Peter Eagles, chairman of the MCC, 'At our last meeting (6 December), the request came up again for suitable overseen use of this agent. Our thinking was, who are we to put people's lives at risk? Our position now is, we want somebody to write it up as a clinical trial and then us be "lenient" on that. Our fear was this could become some kind of first-line therapy. You can only do a probability vote on it. You cannot absolutely say you can or can't use it.'

He revealed that the ball was squarely in the national Department of Health (DoH's) court when it comes to developing a clinical trial, overseeing it and coming back with a document addressing all the MCC's concerns, along with feedback from principal investigators. However, the recent appointment of a new chief director in the DoH's infectious diseases department, plus the recent replacement of the MCC's top in-house legal advisor (after a 3-year hiatus during which the post was empty), have proved to be major challenges. He confirmed that the bedaquiline issue came up at a previous council meeting, and that 'we gave permission and then retracted it [for compassionate use]' Under Section 21 of the Medicines Control Act, they initially allowed individual doctors' use on the strict condition that all adverse events be reported and a monitoring plan drawn up. 'The problem is, not many people understand that Section 21 invariably applies to individual patients, not the masses, Eagles argued. 'We have to protect the public and there was a feeling that it might not be that well-controlled. Let's say, for example, we gave permission for 100 people to use it - that means they must all be monitored. Unless you have a big organisation monitoring, it's liable not to be done and we'd appear to be very negligent ... we don't want counter litigation on those applying for Section 21!'
Eagles' comments, the first willing response from the MCC since the controversy began, lend weight to speculation by treatment activists that original permission was a 'slip' and that revocation was largely a capacity issue.

However, Diacon was sympathetic to the MCC's plight, saying their insistence on a clinical trial with formal assessment of safety and efficacy, plus a 6-monthly review, was 'not unreasonable'. He said most of the data for the FDA's conditional approval came from South Africa, much of it from his own trial. 'The MCC would have no formal means of checking what's happening. Without a formal procedure you expose yourself to some kind of complaint', he pointed out. If the drug was toxic, the MCC would have 'missed an opportunity to find out, which would give you a bad reputation for a decade and you won't find any more trial participants! This business has to be taken very seriously in my opinion.'

While Diacon agreed that the overall context demanded greater urgency, he was hopeful that the FDA ruling would enable the MCC to 'piggyback' their decision on the matter. He said the MCC has developed a reputation for erratic decisions and lengthy approval times for trials, with their lack of expertise posing a real problem. 'It shouldn't be [a wait of] more than 3 months in these kinds of cases. We waited for more than a year for other TB drugs - the Catch-22 is you only know how vital they are afterwards. The MCC gets flooded with applications and they need to prioritise when it comes to humanitarian considerations. There is a certain dysfunctionality. This [bedaquiline] is the first new TB drug in 50 years. We put our first South African patients on it 5 years ago and did the world's first study.' Diacon added that the aim of his current bedaquiline trial is to reduce treatment time from between 18 and 24 months to 9. However, even with positive outcomes and MCC approval, this could take up to 5 years.

Diacon said that in the Western Cape, health authorities quickly took advantage of GenXpert diagnostics, that vastly improved sputum test times while simultaneously detecting rifampicin resistance - enabling speedy and enormously helpful triage of patients. 'They rolled this out so fast that the company ran out of cartridges. Sure, it only detects $\mathrm{TB}$ in $50 \%$ of cases but it's a step in the right direction,' he said. The Western Cape currently has a $60 \%$ MDR TB cure rate. Any upgrade of resources, expertise or systems in (most) other, less fortunate provinces would quickly result in commensurate improvement in cure rates, he emphasised, warning that this would prove costly.

Top pulmonologist appeals for isolation facilities

Von Delft's treating physician was Professor Paul Willcox, one of the country's top pulmonologists and a senior specialist at Groote Schuur Hospital and its innovative eponymous private adjunct hospital. He says that, given the Cape Metropole's pervasive $\mathrm{TB}$ rate (1 000 cases per 100000 people) all hospitals should have isolation facilities. 'They're flooding into all ports of call,' he warned. 'Emergency units and general wards are overrun by drug-sensitive, monoresistant, MDR and XDR patients - there is some awareness of but no physical protection measures like the N95 mask. There's no laminar flow, and generally very few UV lights or isolated negative pressure rooms. Perhaps there are some isolation facilities around the country but I've not seen that in our metro area.' He contends that anybody designing or redesigning an emergency unit should add isolation rooms for patients with potential and known TB.

Dalene von Delft was referred to him with resistance to isoniazide, rifampicin, ethambutol and ethionamide. He expected her to do well on a 6-drug course plus injectable amikacin, which he monitored closely with bi-weekly audiograms. 'She converted very quickly to negative

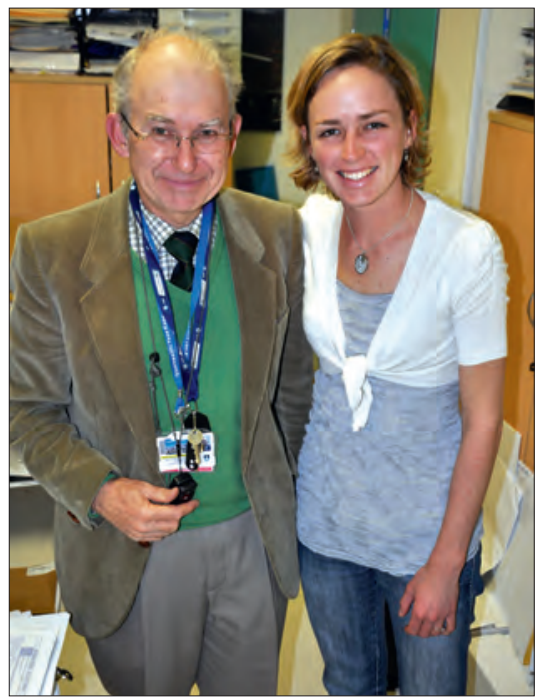

Professor Paul Willcox with his patient.

sputums (within two weeks) and it was fairly localised - but after two and a half months her audiograms deteriorated while she subjectively noted that her hearing was worsening,' he explained.

Von Delft readily agreed to stop the amikacin since her disease was improving, 


\section{IZINDABA}

but feared that continuing without substitution was dicey. However, there were no available or affordable substitutes at the time. 'With somebody doing well there's always the risk of failure or relapse if you weaken the regime, explained Willcox. Enter Diacon, another worldclass senior colleague, who pushed the application for bedaquiline through, 'not strictly for compassionate use in terms of a failing treatment, but to maintain the improvement she was having,' Willcox stipulated.

Von Delft's husband, Arne, developed pleuritis two months after she was diagnosed with MDR TB and fell sick with flu-like symptoms four times over the ensuing two years. He told Izindaba that he had trusted his immune system and adapted his lifestyle accordingly, 'deferring all exams, overtime and night work'. While tests showed that his body had been exposed to TB, nothing developed and he has remained asymptomatic, with chest X-rays normal.

Today, the von Delfts passionately back Willcox's views on slack TB prevention practice in the field, including 'unnecessary' tours of MDR TB hospitals offered to medical students.

\section{From TB 'victim' to global activist}

Speaking on the eve of a flight to New Jersey in the USA (12 January) to make yet another global appeal for more TB drugs - this time at a Janssen leadership summit - Dalene von Delft says her abiding emotions post-cure are simple happiness and gratitude for being healthy. 'It's amazing to be healthy ... that's really changed me. The little complaints you had about life seem so insignificant.' The couple will shortly be travelling again, this time as guests of USAID, to Washington DC for a 'TB Week' conference from 18 - 24 March (International TB day is on $24 \mathrm{March}$ ).

Far from limiting Dalene von Delft's horizons, MDR TB seems to have significantly widened them - good news for the majority of her less fortunate fellow South Africans.

\section{Chris Bateman}

chrisb@hmpg.co.za

S Afr Med J 2013;103(3):134-136. DOI:10.7196/SAMJ.6752 